\title{
EFFECT OF TOPICAL OZONE THERAPY ON DENTURE- RELATED TRAUMATIC ULCERS: A CASE REPORT
}

\section{AUTHORS}

Almina Muric 1, Bilge Gokcen Rohlig 2, Tamer Celakil 2

1 Department of Prosthodontics, Faculty of Dentistry, Istanbul Aydin University, Istanbul, Turkey.

2 Department of Prosthodontics, Faculty of Dentistry, Istanbul University, Istanbul, Turkey.

\section{ABSTRACT}

Introduction: Dental related oral mucosal lesions are most often complications of wearing removable dentures. Painful lesions treatment beside removing ethiologyical factor is symptomatic therapy. Recent investigations of ozone have reported that ozone can induce the wound healing. Case raport: A patient with three ulcerative lesions subsequently developed as a result of wearing implant retained overdenture were included in the study. Each lesion recived conventional care whereas tested lesion recived topical gaseous ozone therapy additionaly. Ozone was applied directly on the musocal lessions for three times in 1 week (baseline-1.day-3.day). The basic result were changes in greatest dimension of every lesion from first treatment and at days 1 and 3. Conclusion: The current case report showed positive effect of gaseous ozone on accelerating the process of healing and pain reduction but future clinical studies are needed to confirm these findings.

Key words: ozone, ozone in dentistry, wound healing, traumatic lesions

\section{INTRODUCTION}

According to the World Health Organization, the Removable dentures are highly successful treatment option to gain a satisfying restoration that fulfills functional and aesthetic demands of edentulous patients, however high frequency of heterogeneous oral mucosal lesions is associated with their wearing.

Denture related oral mucosal lesions may represent acute or chronic damage of epithelium and lamina propria (connective tissue) [1]. They can also be reactions to denture base materials, denture plaque, yeast, poor retention and mechanical trauma [2].

Denture-related ulcers are may vary in size and dimension, and they are characterized by a white or yellowish central clear area with an erythematous halo $[3,4]$. Most comon complaint is mild to severe pain whitch persist for 7-10 days and effects the quality of life [1].

The aim of treatment is to remove ethiologyical factor, relieve the symptoms and induce the dynamic and complex biological process of closing the wounded area(1). Recent investigations of ozone have reported that ozone can induce the wound healing $[5,6,7,8]$

Ozone is unstable triatomic molecule, consisting of three oxygen atoms (03) which has been used for almost 150 years in medicine as a therapy for several disease. [5] There are several known actions of ozone on human body, such as anti-microbial, immunostimulating, antihypoxic, analgesic, detoxicating, bioenergetics and biosyn- thetic (activation of the metabolism of carbohydrates, proteins \& lipids) [8].

In dentistry ozone is used for treatment of early carious lesions, sterilization of cavities, disinfection of root canals, periodontal pockets, bleaching of discolored teeth, desensitization of extremely sensitive teeth, periimplantitis, enhancing epithelial wound healing, and as a denture cleaner [9].

\section{STUDY OBJECTIVE}

The aim of this clinical case report was to evaluate the effect of topical ozone therapy on healing time and pain level of denture-related lesions of the oral mucosa in an mandibular edentulous individual.

\section{MATHERIAL AND METHODS}

A 58-years old edentulous female patient with newly fabricated implant retained overdenture was referred to the Department of Maxillofacial Prosthodontics due to solitary and painful ulcerative lesion (Fig 1). Clinical examination revealed three ulcerative lesions related to her complete denture in mandible (Fig 2). 


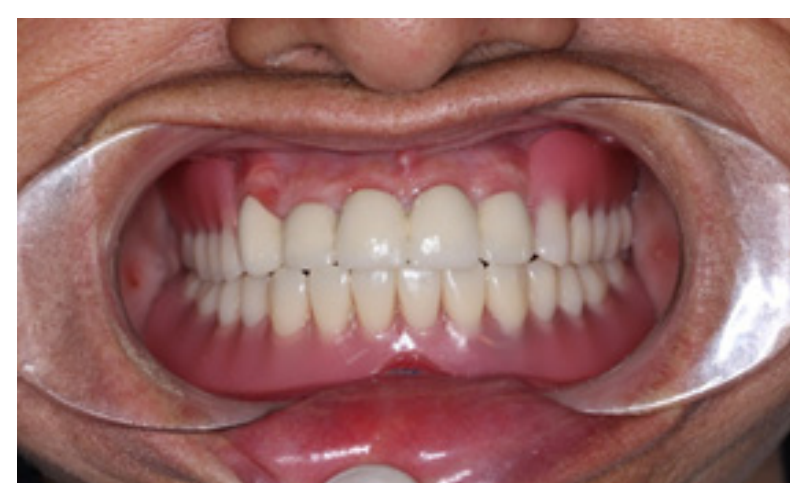

Figure 1

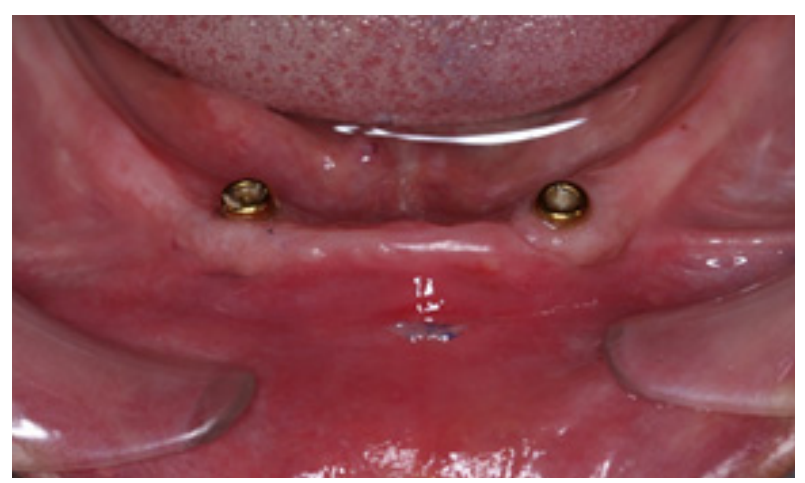

Figure 2

A single operator marked and measured dimensions of three lesions (Fig 3). Digital photographs of each lesion were also taken. The same operator adjusted denture margins (Fig 4) and occlusion, upon which the smaller two lesion (control lesion) located posterior buccal side was left to heal without any further treatment whereas the larger lesion (test lesion) located anterior buccal side was assigned to receive application of a topical ozone therapy.

Topical ozone therapy was applied directly on the affected area three times with 2 minutes within the first 1 week (baseline-1.day-3.day) (Fig 5). The primary outcome measures were changes since baseline in each lesion's greatest dimension at days 1 and 3 . Consultation with the digital photographs ensured the correct control lesion was measured at the follow-up visits. During the night, the dentures were immersed in water after the standard cleaning procedures. Participants were instructed to not take any other medication for the ulcers.

\section{Ozone exposure:}

An oxygen activation generator (OzonytronX, Biozonix $\mathrm{GmbH}$, Munich, Germany) was used for ozone exposure. This device generates high-frequency bio-oxidative ozone with voltage power. Ozone intensity of $60 \%$ was used and the concentration in the operation field was 10 $100 \mu \mathrm{g} / \mathrm{ml}$.

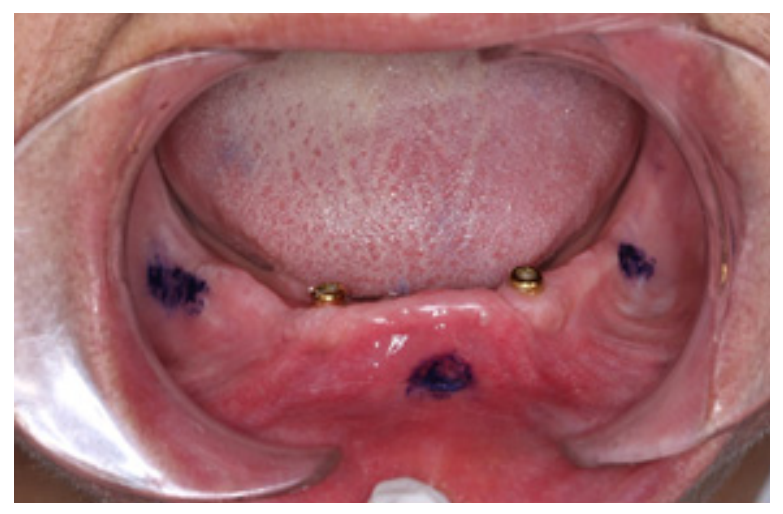

Figure 3

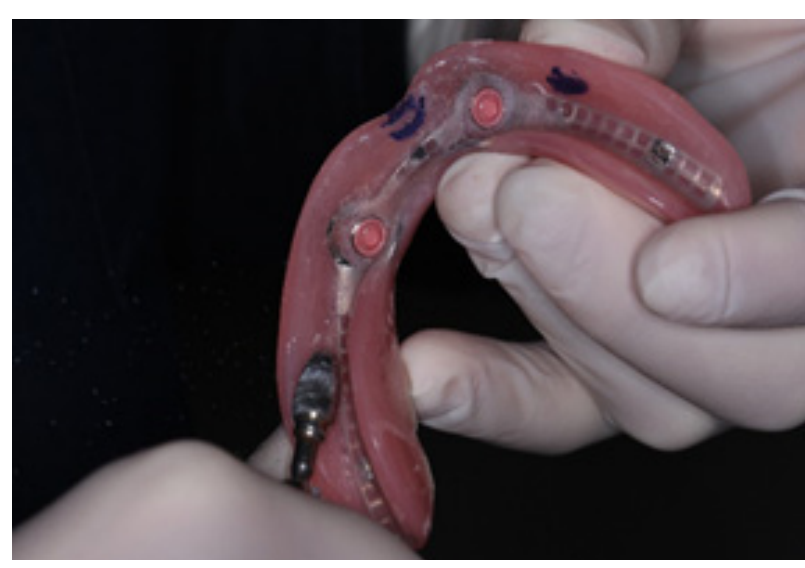

Figure 4

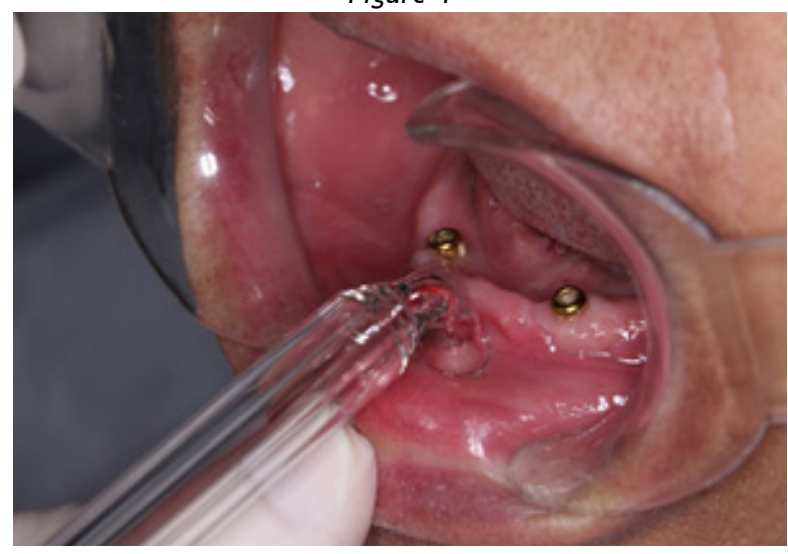

Figure 5

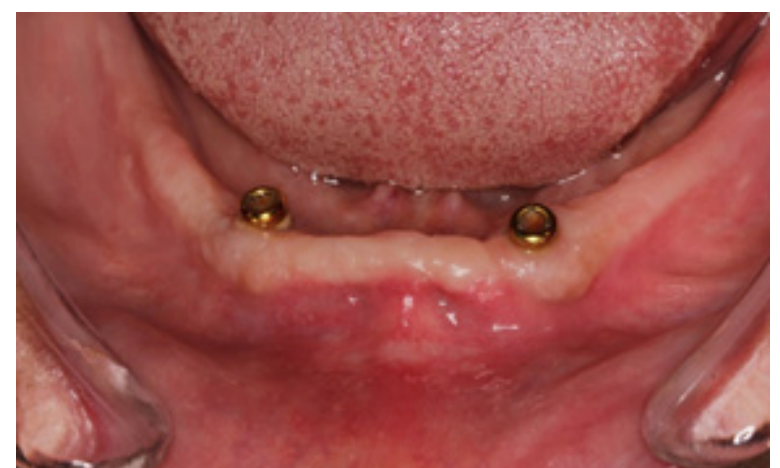

Figure 6 
Ozone generator was emitted electromagnetic field and transfom oxygen into ozone. This noble gasses were transmitted to the treated area with glass omega probe (gingiva, Gl probe) and gasses were suitable for soft tissue stimulation.

\section{RESULTS}

At baseline, test lesion treated with the topical ozone were $6.3 \mathrm{~mm}$ in greatest dimension, and the smaller lesions receiving usual care were $3 \mathrm{~mm}$ and 3.4 $\mathrm{mm}$. 24 hours after first application of topical ozone therapy and usual care of lesions, the greatest dimensions were $6.1 \mathrm{~mm}$ (test lesion), $3 \mathrm{~mm}$ and $3.4 \mathrm{~mm}$ (control lesion). 3 days after, the greatest dimensions were 3 $\mathrm{mm}$ (test lesion), $2 \mathrm{~mm}$ and $2.1 \mathrm{~mm}$ (control lesion) (Fig $6)$.

\section{DISCUSSION}

In this case report we found that tratment of a denture related lesions with topical application of ozone can accelerete faster healing and decrease pain intesity compared to usual care.

Removable dentures are the most common treatment choice in edentulous patients. In most cases edentulocity is accompanied with thinner epithelium, reduced resilience and reduced capacity for tissue regeneration as an effect of aging process [10]. Due to different systematic diseases, use of tobacco, use of xerogenic medications, poor oral hygiene oral mucosa, consequently becomes more vulnerable. Oversized dentures accompanied with this factors leads to mucosal lessions as a most common complications in denture wearers.

Denture related oral mucosal lesions may represent acute or chronic damage of epithelium and lamina propria (connective tissue) [1]. They can also be reactions to denture base materials, denture plaque, yeast, poor retention and mechanical trauma [2].

Denture-related ulcers are may vary in size and dimension, and they are characterized by a white or yellowish central clear area with an erythematous halo. (bascones, cavon, vuruk 9111 ). Most comon complaint is mild to severe pain whitch persist for 7-10 days and effects the quality of life [1].

The aim of treatment is to remove ethiologyical factor, relieve the symptoms and induce the dynamic and complex biological process of closing the wounded area [1].

Usual care for denture-associated traumatic ulcers demand adjustment of the margins and occlusal adaptation of the dentures [10], accompained with symotomatic (pain relife) therapy combined with instruction in home denture hygiene and careful observation.

After 1840. when Christian F.Schonbein, Father of ozone therapy, had introduced word ozone, it becomes one of the most controversial research topics in medicine [8]. 1896 Nikola Tesla patented the first Ozone generator and by that facilitate the use of this gas.1932 for the first time Edward Fisch used ozone for control of infections in dental practice. [9]

Ozone is a natural pale blue gas that can be found in the atmosphere which nowdays is widely used in medicine and dentistry as strong oxidant with high biocompatibility and healing effects. Due to it's anti-microbial, anti-inflammatory, analgesic and immune-stimulating properties and lack of toxicity ozone is found an implementations in different therapy modalities $[9,11,12]$.

Besides the fact that is used in dentistry for treatment of carious lesions, root canal disinfection, wound healing, plaque control, disinfection of dentures, pain relief ozone is recent used in TMJ disorder treatments [11].

Ozone has been used as gaseous form (oxygen/ozone gas) or aqueous form (ozonated water ,ozonated oil).

Huth et al. showed that the both gaseous and aqueous ozone have been reported to exert antimicrobial effects. The aqueous form of ozone, as a potential antiseptic agent, showed less cytotoxicity than gaseous ozone or established antimicrobials (chlorhexidine digluconate 2\%, $0.2 \%$; sodium hypochlorite $5.25 \%, 2.25 \%$; hydro- gen peroxide $3 \%$ ) under most conditions. Therefore, aqueous ozone maintains optimal cell biological characteristics in terms of biocompatibility for oral application. [13]

Fillipi et al. have investigated the Influence of Ozonised Water on the epithelial wound healing process in the oral cavity and reported that the application of ozonised water clearly showed an acceleration of wound healing within the first 48 hours, resulting in earlier epithelial wound closure after 7 days [14].

The mechanism of ozone effect in a wound healing is still unclear. It is suggested that activates higher expression of cytokines, especially TGF-B1 wich induce the proliferation of fibroblasts and leads to a pronounced acceleration of wound healing $[15,16]$.

In recent research investigating the effects of systemic and topical ozone applications on alveolar bone healing following tooth extraction Erdemci et al. found that ozone has beneficial effects on wound healing for hard and soft tissue. Small doses of ozone can activate biochemical mechanisms and reactivate the antioxidant system [17]. Kazancioglu et al. and Yıldırım AO et al. reported that according to histopathological examination gaseous ozone reduces inflammation and edema and is useful in wound healing on both soft and hard tissue $[18,19]$

Application of gaseous ozone has also been shown to be effective in facilitating oral wound healing after highdose radiotherapy. Petrucci et al. reported that the application of 15 days of ozone therapy was beneficial in the treatment of bisphosphonate related osteonecrosis of the jaws [20]).

Agrillo et al. performed 20 tooth extractions in 15 patients with avascular bisphosphonate-related jaw osteonecrosis and reported that ozone was effective when used for 7 days before and after the tooth extraction [21]. Contrarily, Matsumura et al. reported that ozone $(0.5 \mathrm{~g} / \mathrm{h}$ for $5 \mathrm{~h})$ does not have a major impact on the stimulation of gingival cells for osteoblastic activity in the regeneration of the periodontium around implant [22].

Bayer et al. used gaseous ozone to comparis laser and ozone treatments on oral mucositis in an experimental model. Ozone was applied with $80 \%$ oxygen for $120 \mathrm{~s}$ per day, for 5 days. The data of this study suggest that both laser and ozone therapies have positive effects in the treatment of oral mucositis. In respect of TGF-B, no statistically significant difference was observed between the groups. However, LLLT therapy seems to be more effective than ozone therapy [23]. 
In this case report gaseous ozone was topicaly applied directly on the affected area three times with 2 minutes within the first 1 week (baseline-1.day-3.day). Ozone intensity of $60 \%$ was used and the concentration in the operation field was $10-100 \mu \mathrm{g} / \mathrm{ml}$. It was observed that test lesion treated with the topical ozone showed the high rate of healing and pain decrese, compared to the lesions receiving usual care.

Within all limitations of this case report it is obviously that Ozone can have important role in traumatic ulcer therapy.

\section{CONCLUSION}

The result of this case report suggest that application of topical ozone may represent a novel, effective treatment for accelerating the healing process and pain reduction inmucosal lesions associated with complete dentures. The current case report showed that future studies are needed to confirm these findings.

\section{Disclosure/ Acknowledgements}

For use of Ozone Therapy in this Case Report, from patient it was taken written confirmation.

This research was carried out without funding.

The authors have stated explicitly that there are no conflicts of interest in connection with this article.

\section{REFERENCES}

1. Wagner VP, Meurer L, Martins MAT, Danilevicz CK, Magnusson AS, Marques MM, et al. Influence of different energy densities of laser phototherapy on oral wound healing. J Biomed Opt [Internet]. 2013;18(12):128002. Available from: http: / / www.pubmedcentral.nih.gov/articlerender.fcgi?artid=4019369\&tool=pmcentrez\&rendertype=abstract

2. Andersen IB, Bonnevie O, Jorgensen T, Sorensen TI. [Peptic ulcer in Denmark, 1981-1993. Analysis of data from national patient registries]. UgeskrLaeger. 1999;161(11).

3. Bascones A, Figuero E EG. Ulceras orales. Med Clin. 2005;125:590-7.

4. Talacko AA, Gordon AK AM. The patient with recurrent oral ulceration. Aust Dent J. 2010;55(1):14-22.

5. Borges GÁ, Elias ST, da Silva SMM, Magalhães PO, Macedo SB, Ribeiro APD, et al. In vitro evaluation of wound healing and antimicrobial potential of ozone therapy. J Cranio-Maxillofacial Surg [Internet]. 2017;45:364-70. Available from: http://www.sciencedirect.com/science/article/pii/S1010518217300057

6. Sahin H, Simsek T, Turkon H, Kalkan Y, Ozkul F, Ozkan MTA, et al. The acute effects of preoperative ozone theraphy on surgical wound healing. Acta Cir Bras. 2016;31(7):472-8.

7. Sagai M, Bocci V. Mechanisms of Action Involved in Ozone Therapy: Is healing induced via a mild oxidative stress? Med Gas Res [Internet]. 2011;1(1):29. Available from: http: / /www.pubmedcentral.nih.gov/articlerender.fcgi?artid=3298518\&tool=pmcentrez\&rendertype=abstract

8. Kumar P, Tyagi P, Bhagawati S, Kumar A. Current interpretations and scientific rationale of the ozone usage in dentistry: $\mathrm{A}$ systematic review of literature. Eur J Gen Dent [Internet]. 2014;3(3):175. Available from: http: / / www.ejgd.org/text.asp?2014/3/3/175/141658

9. Srinivasan K. The Application of Ozone in Dentistry: A Systematic Review of Literature. Sch J Dent Sci. 2015;2(6):373-7.

10. Jivanescu A, Borgnakke WS, Goguta L, Erimescu R, Shapira L, Bratu E. Effects of a Hydrogel Patch on Denture-Related Traumatic Ulcers; an Exploratory Study. J Prosthodont. 2015;24(2):109-14.

11. T.Celakil, A. Muric, B.G.Rohlig, G.Evlioğlu HK. Effect of high-frequency bio-oxidative ozone therapy for masticatory muscle pain: a double-blind randomised clinical trial. J Oral Rehabil. 2017;44(6):442-51.

12. Lynch E. Comment on "The application of ozone in dentistry: A systematic review of the literature." J Dent. 2009;37(5):402-6.

13. Huth KC, Jakob FM, Saugel B, Cappello C, Paschos E, Hollweck R, et al. Effect of ozone on oral cells compared with established antimicrobials. Eur J Oral Sci. 2006;114(5):435-40.

14. Andreas F. "The influence of ozonised water on the epithelial wound healing process in the oral cavity." Surgery. 2001;1(14).

15. Mustoe, T.A., Pierce, G.F., Thomason, A., Gramates, P., Sporn, M.B., Deuel TF. "Accelerated healing of incisonal wounds in rats induced by transforming growth factor-B. Science (80- ). 1987;237(4820):1333-6.

16. Beck LS, Chen TL, Hirabayashi SE, DeGuzman L, Lee WP, McFatridge LL, et al. Accelerated healing of ulcer wounds in the rabbit ear by recombinant human transforming growth factor-beta 1. Vol. 2, Journal of controlled release : official journal of the Controlled Release Society. 1990. p. 273-82. 
17. Erdemci F., Gunaydin Y., Sencimen M., Bassorgun I, Ozler M, Oter S, Gulses A, Gunal A, Sezgin S, Bayar GR, Dogan N GI. Histomorphometric evaluation of the effect of systemic and topical ozone on alveolar bone healing following tooth extraction in rats. Int J Oral Maxillofac Surg. 2014;43(6):777-83.

18. Kazancioglu HO, Kurklu E, Ezirganli S. Effects of ozone therapy on pain, swelling, and trismus following third molar surgery. Int J Oral Maxillofac Surg [Internet]. 2014;43(5):644-8. Available from: http://dx.doi.org/10.1016/j.ijom.2013.11.006

19. Yıldırım AO, Eryılmaz M, Kaldırım U, Eyi YE, Tuncer SK E, Al M et. ) Effectiveness of hyperbaric oxygen and ozone applications in tissue healing in generated soft tissue trauma model in rats: an experimental study. Ulus Travma Acil Cerrahi Derg. 2014;20:167-175.

20. Petrucci MT, Gallucci C, Agrillo A, Mustazza MC, Foà R. Role of ozone therapy in the treatment of osteonecrosis of the jaws in multiple myeloma patients. Haematologica. 2007;92(9):1289-90.

21. Agrillo, Allesandro MD, PhD; Ungari, Claudio MD; Filiaci, Fabio MD; Priore, Paolo MD; lannetti, Giorgio MD P. Ozone Therapy in the Treatment of Avascular Bisphosphonate. J Craniofac Surg. 2007;18(5):1071-5.

22. Matsumura K, Hyon SH, Nakajima N TS. Effects on gingival cells of hydroxyapatite immobilized on poly(ethylene- co-vinyl alcohol). J Biomed Mater Res. 2007;82:288-95.

23. Bayer S, Kazancioglu HO, Acar AH, Demirtas N, Kandas NO. Comparison of laser and ozone treatments on oral mucositis in an experimental model. Lasers Med Sci [Internet]. 2017;673-7. Available from: http://link.springer.com/10.1007/s10103-017-2166-1 